\title{
Fundamental principles of earthquake resistance calculation to be reflected in the next generation regulations
}

\author{
Oleg Mkrtychev ${ }^{1, *}$, Guram Dzhinchvelashvili ${ }^{1}$ \\ ${ }^{1}$ Moscow State University of Civil Engineering, Research laboratory "Safety and Seismic Resistance \\ of Structures", 129337 Moscow, Russia
}

\begin{abstract}
The article scrutinizes the pressing issues of regulation in the domain of seismic construction. The existing code of rules SNIP II-7-81* "Construction in seismic areas" provides that earthquake resistance calculation be performed on two levels of impact: basic safety earthquake (BSE) and maximum considered earthquake (MCE). However, the very nature of such calculation cannot be deemed well-founded and contradicts the fundamental standards of foreign countries. The authors of the article have identified the main problems of the conceptual foundation underlying the current regulation. The first and foremost step intended to overcome the discrepancy in question is renunciation of the $K_{1}$ damage tolerance factor when calculating the BSE. The second measure to be taken is implementing the response spectrum method of calculation, but the $\beta$ spectral curve of the dynamic response factor must be replaced by a spectrum of worst-case accelerograms for this particular structure or a spectrum of simulated accelerograms obtained for the specific construction site. Application of the response spectrum method when calculating the MCE impact level makes it possible to proceed into the frequency domain and to eventually obtain spectra of the accelerograms. As a result we get to know the response of the building to some extent, i.e. forces, the required reinforcement, and it can be checked whether the conditions of the ultimate limit state apply. Then, the elements under the most intense load are excluded from the design model the way it is done in case of progressive collapse calculations, because the assumption is that these elements are destroyed locally by seismic load. This procedure is based on the already existing design practices of progressive collapse calculation.
\end{abstract}

\section{Introduction}

About a quarter of Russian territory is located in seismic areas. Considerable funds are allocated annually for seismic safety measures. The extent of anti-seismic reinforcement is determined based on calculations of seismic resistance under the spectrum theory mandated by regulations. However, the buildings designed under the regulations in effect do not

* Corresponding author: mkrtychev@yandex.ru 
ensure the level of seismic capacity required for intense earthquakes. This is corroborated by the implications of the Spitak (1988) and Neftegorsk (1995) earthquakes where the buildings were almost completely destroyed.

The recently developed design regulations allow behavior of material beyond elasticity. Non-linear behavior of structures is expected, even an assumption is made about the possible collapse of individual structural components which must be relatively accessible for investigation and repair and whose destruction does not damage the whole structure severely.

Structural designers thus have to engineer structures so that intense earthquakes inflict damage below a certain threshold, i.e. so that damage could be manageable and allowable.

Development of next generation regulations [1], which could be applied in practice by large communities of engineers, is the task of prime importance for anti-seismic engineering.

A broad implementation of such a standard presumes a high skill level of designers who master both non-linear static and dynamic methods of calculation. Besides, a certain scope of theoretical and experimental studies must be carried out in such domains as designing non-linear models for materials, non-linear computational dynamic models of reinforced concrete and steel structures while taking care of interaction with the foundation soil. Also, models of seismic impact must be elaborated for an earthquake as a nonstationary random process.

Over the past few decades, publications, reports and forum speeches produced by various scientists have stated the idea of replacing one-stage calculation with the two-stage method. This idea is based on acknowledgement of the probabilistic nature of earthquakes, whose intensity depends on their frequency (recurrence) for physical reasons. In other words, relatively weak earthquakes which occur more frequently do not dictate assumptions of considerable destruction, and the other way around, in case of intense but rare earthquakes it makes sense to plan local damage and non-elastic deformations and to assume such kind of damage albeit with no major life- and health-threatening collapse.

\section{Two-level design calculation for seismic resistant structures}

The engineering analysis of exposure to strong earthquakes that occurred during the validity period of SNIP P-7-81* is indicative of the fact that the regulations in force do not always ensure seismic stability of buildings and structures built in full compliance with the initial design. A range of cases demonstrate that robustness of some buildings was not ensured to the full extent [2] when the intensity of seismic impact was close to forecast or higher.

This is caused by the following circumstances.

The regulations at hand take account of non-linearity only by introducing a single integrated reduction factor $\dagger$ into the response spectrum method.

In fact, the calculation is done in a deterministic set-up, however, seismic impact is a highly random process and any deterministic approach will fail to determine seismic resilience of the designed buildings and structures.

Assurance of the required seismic resistance level is only possible by applying methods of the probability theory, the theory of random processes and the structural reliability theory.

\footnotetext{
' SNIP II-7-81* makes use of a magnitude which is the reverse of the reduction factor, that is the $K_{1}$ damage tolerance factor
} 
At the moment a new conceptual framework is overdue in appearing which would make it possible to design buildings and structures protected by a certain level of seismic resistance.

Average recurrence of earthquakes of a given intensity for a particular area can be obtained from the maps of general seismic zoning [3] (Table 1).

Table 1. Average recurrence of earthquakes according to the maps of general seismic zoning

(General Seismic Zoning 2012).

\begin{tabular}{|c|c|}
\hline Map of General Seismic Zoning & Recurrence period, years \\
\hline General Seismic Zoning -2012 A & 100 \\
\hline General Seismic Zoning -2012 B & 500 \\
\hline General Seismic Zoning -2012 C & 1000 \\
\hline General Seismic Zoning -2012 D & 2500 \\
\hline General Seismic Zoning -2012 E & 5000 \\
\hline General Seismic Zoning -2012 F & 10000 \\
\hline
\end{tabular}

In Europe [4, 5] and many other countries buildings are engineered involving the maximum considered earthquake (MCE) which may occur with 0,1 probability once in 50 years. In other words, most EU countries ${ }^{\ddagger}$, USA, Canada, Japan etc. assume the recurrence period for $\mathrm{MCE}$ to be $T_{\mathrm{SSE}}=475$ years.

At the same time the structure of a building or facility must be engineered so that it could withstand a seismic impact which has a higher probability of occurrance than MCE, i.e. the so-called basic safety earthquake (BSE), which may occur once in 50 years with a probability of 0,5 . The recurrence period of BSE is $T_{\mathrm{OBE}}=95$ years $\$$.

Below we present the approach proposed by us, which appears to be the most wellfounded in our view.

\subsection{Basic safety earthquake}

A frequent earthquake must be expected to happen with a probability close to 1 on the specific construction site over the building's lifetime (50 - 100 years for most industrial and civil buildings and facilities).

Therefore, the seismic load of a given intensity with the recurrence period of once in a hundred years ranks similarly with, for instance, peak wind and snow loads whose recurrence periods are much shorter. Hence, the principles of defining earthquake loads for buildings and structures must be the same as for wind and snow loads.

The proposal is to make calculations for a specific intensity of seismic stress based on the ultimate limit state with no account taken of the reduction factor (by actually assuming that $K_{1}=1$ ), the way it is done for operational ${ }^{* *}$ loads.

Design calculations for seismic loads fitting into the serviceability limit state combined with the requirement to preserve operability of the building appear impractical. Any earthquake in any case dictates that the state of load-bearing structures of the building be examined.

\footnotetext{
${ }^{*}$ The British value is $T_{\mathrm{SSE}}=2500$ years.

${ }^{\S}$ Under the Japanese regulations, $T_{\mathrm{OBE}}=30-50$ years [6].

${ }^{* *}$ Wind, snow etc.
} 
Since the ultimate limit state suggests mostly elastic behavior, the response spectrum method can be considered applicable.

\subsection{Maximum considered earthquake}

Over the lifetime of the building on a specific construction site a 'rare' earthquake must be expected with a certain probability and a meaningfully defined recurrence period. Buildings and structures must endure earthquakes of a specified intensity without local or overall failure of load-bearing elements.

The recurrence period for the maximum considered earthquake can be determined as follows.

Reliability theory includes definition of an unconditional probability that an adverse event might happen to a person in the course of a year (severe health damage, fatal outcome). This probability accounts for about $3000 \cdot 10^{-7}$ persons-year/ (table 2) [7].

Table 2. Fatal outcome probability for a person throughout a year

\begin{tabular}{|c|c|}
\hline Conditions and activities & $10^{-7}$ persons/year \\
\hline Car accidents & 2700 \\
\hline Fires and explosions & 400 \\
\hline Water bodies & 280 \\
\hline Handling of machines & 100 \\
\hline Air traffic & 75 \\
\hline Electricity & 51 \\
\hline Lightning & 5.5 \\
\hline Public transportation & 0.45 \\
\hline Radioactivity & 0.05 \\
\hline
\end{tabular}

Let us assume this unconditional probability of fatal outcome to be a standard maximum allowable value, i.e. $\left[P_{\text {fatal }}\right]=3 \cdot 10^{-4}$ persons/year .

Than the design calculations must be performed based on the condition that

$$
P_{1} \leq\left[P_{\text {fatal }}\right]
$$

where $P_{1}$ is the probability of a fatal outcome for a person per year for a maximum considered earthquake in the specific area of construction and the specific type of structure.

Now the $P_{1}$ probability must be determined, with the mean reference recurrence period of a maximum considered earthquake being $T_{\mathrm{SSE}}=500$ years.

The probability of an MCE occurring at the specific construction site throughout one year is given by

$$
P_{\text {year }}=\frac{1}{500}=0.002
$$

According to a comprehensive study of implications of severe earthquakes [8] which was performed based on the lessons learned of the Russian EMERCOM, the reasonable probability of a structure's collapse $P_{\text {collapse }}$ due to a disastrous collapse (of MCE scale) may be assumed equal to 0,1 :

$$
P_{\text {collapse }}=0.1
$$

The probability of a person being inside the building is tentatively $P_{\text {building }}=0.6$, while the probability of a person being hurt by the building's failure is $P_{\text {injury }}=0.8$. 
Therefore, the probability of a fatal outcome for a person per year due to MCE should be

$$
P_{1}=P_{\text {year }} \cdot P_{\text {collapse }} \cdot P_{\text {building }} \cdot P_{\text {injury }}=0.002 \cdot 0.1 \cdot 0.6 \cdot 0.8=96 \cdot 10^{-6} \approx 1 \cdot 10^{-4} \text { persons } / \text { yea }(4)
$$

Hence,

$$
P_{1}=1 \cdot 10^{-4} \text { persons } / \text { year }<\left[P_{\text {fatal }}\right]=3 \cdot 10^{-4} \text { persons } / \text { year } .
$$

In other words, if we assume the mean recurrence period to be $T_{\mathrm{SSE}}=500$ years and the probability of the building's collapse due to the maximum considered earthquake to be 0.1 , than the probability of fatality for a person per year will be close to the unconditional probability and is not going to exceed it.

\section{MCE impact calculation}

MCE calculations must involve computation of ad-hoc limit states. Since this research is dedicated to structural states which are close to limit states and are subject to substantial non-elastic plastic strain, the non-linear nature of the structural behavior must be explicitly taken into account. The latter is only possible by using non-linear static and dynamic methods.

At the moment these methods can be utilized in design calculations made for unique buildings and facilities, for which special research and development support is provided by organizations possessing the relevant qualifications.

Design contractors who carry out design effort for standardized construction could employ the following approach for MCE calculations.

The suggestion would be to introduce the response spectrum method into the calculation of MCE impact level, as well as to involve actual worst-case accelerograms for the specific structure, while switching in such a way to the frequency domain and obtaining a spectrum of accelerograms. As a result, we get to know the response of the facility to some extent: forces, the required reinforcement, whether conditions of the ultimate limit state are fulfilled. However, the seismic impact will always deviate from the findings and differ from the impact used for the calculations. This is why it has to be checked whether another earthquake could cause the building to collapse in an avalanche-like way. The results obtained from MCE-scale earthquake calculation make it possible to identify the most intensely loaded elements which are than excluded from the computational model the way it is done for calculations of resistance to progressive collapse. Most structural designers have mastered this method successfully.

It should be noted that MCE calculation is in this case the same as progressive collapse calculation frameworked by the input seismic loads and the relevant scenarios of local failures. If the structure is not considered subject to progressive collapse, then the noncollapse criterion should be viewed as completed.

This approach is equipped to provide for the required level of seismic stability and safety of buildings and structures located in seismic areas.

\section{Conclusions}

This article has presented a philosophy of two-level structural design calculation for buildings exposed to earthquakes. The approach elaborated by the authors offers the possibility of designing buildings and structures with a predetermined seismic resistance and a required level of safety for human life and health. 


\section{References}

1. Proprietary standard of Moscow State University of Civil Engineering (National Research University 2015. Seismic resistance of buildings and structures. Design parameters (Moscow State University of Civil Engineering, Moscow, 2015)

2. O. V. Mkrtychev, G. A. Dzhinchvelashvili Accounting for non-linearity in the seismic resistance theory (hypotheses and fallacies) (Moscow State University of Civil Engineering, Moscow, 2012)

3. V. I. Ulomov, L. S. Shumilina Challenges of seismic zoning in Russia (All-Russian Research Institute for Technical Progress and IT in Construction of the Federal agency of construction, housing and housing services of the Russian Federation, Moscow, 1999)

4. Eurocode 8: Design of Structures for Earthquake Resistance - Part 1: General Rules, Seismic actions and Rules for Buildings (European Committee for Standardization, Brussels, 2003)

5. M. Fardis, K. Gulvanesian Eurocode 8: a reference for designers. Design of seismic resistant structures under EN 1998-1 and EN 1998-5. Eurocode 8: General provisions for design of seismic resistant structures, seismic impact, rules for designing buildings and retaining structures (Moscow State University of Civil Engineering, Moscow, 2015)

6. Edoardo M. Marino, Masayoshi Nakashima, Khalid M. Mosalam Engineering Structures $27827-840$ pp. (2005)

7. G. Augusti, A. Baratta, F. Casciati Probabilistic methods in structural engineering (Stroyizdat, Moscow, 1988)

8. M. A. Shakhramanyan Seismic risk assessment and forecasting earthquake effects for rescue operations (All-Russian Research Institute for Civil Defense and Emergencies, Moscow, 2000) 